\title{
FITOPLÂNCTON DO ESTUÁRIO DO RIO JAGUARIBE, (ITAMARACÁ, PERNAMBUCO, BRASUL): BIOMASSA.
}

Terezinha Lúcia dos SANTOS-FERNANDES ${ }^{(1)}$

(1) EMPARN - Empresa de Pesquisas Agropecuária do Rio Grande do Norte José Zanon de Oliveira PASSAVANTE ${ }^{(2)}$

Maria Luise KOENING ${ }^{(2)}$

Sílvio José de MACÊDO(2)

(2) UFPE - Departamento de Oceanografia Apoio financeiro: $\mathrm{CNPq}$

\section{RESUMO}

Estudos visando a determinação da biomassa fitoplanctônica foram desenvolvidos em três (3) estações fixas no estuário do nio Jaguaribe (Itamaracá -PE - Brasil), com a finalidade de se conhecer o grau de eutrofização do ecossistema. Mensalmente, de maio/95 a julho/96 foram coletadas amostras na camada superficial da água, em dois regimes de marés, sendo empregada a análise espectrofotométrica descrita por Strickland \& Parsons (1968), para determinacção da biomassa fitoplanctônica através da clorofila $a$. Os valores de clorofila-a total registrados no estuário do rio Jaguaribe durante a baixa-mar, variaram entre 4,06 a $35,49 \mathrm{mg} \cdot \mathrm{m}^{-3}$, ocorrendo respectivamente nos meses de setembro e outubro/95 na estação 2 . O valor médio para este regime de maré foi de $13,04 \mathrm{mg} \cdot \mathrm{m}^{-3}$. Na preamar, os valores variaram entre 1,35 a $38,47 \mathrm{mg} \cdot \mathrm{m}^{-3}$, sendo o menor valor registrado no mês de março/96 na estação 2 , e o máximo no mês de junho/96 na estação 1 . O valor médio neste regime de maré foỉ de 9,90 $\mathrm{mg} . \mathrm{m}^{-3}$. Os resultados obtidos permitiram caracterizar a área como altamente produtiva, devido aos elevados índices de biomassa fitoplanctônica principalmente durante o período chuvoso.

Palavras chave: Estuário; Clorofila-a; Fitoplâncton; Biomassa.

\section{ABSTRACT}

Phytoplankton of the Estuary of thr River Jaguaribe (Itamaracá Pernambuco - Brazil): Biomass

Studies about the phytoplankton biomasss were developed in three fixed stations at the estuary of the river Jaguaribe (Itamaracá-Pernambuco-Brazil) in order to recognize the grade of euthrophication of the ecosystem. From May/95 to July/96 samples were monthly collected at the surface and at diurnal low and high tide. Spectrophotometric analyses were made following the recommendation of Strickland \& Parsons (1968), for the measurement of phytoplankton chlorophyll $a$ concentration. The chlorophyll $a$ values ranged from 1.35 to $38.47 \mathrm{mg} \cdot \mathrm{m}^{-3}$ found in September and October/95, respectively at station 2 . The average value for low tide was $13.04 \mathrm{mg} \cdot \mathrm{m}^{-3}$. At high tide,values varid from 1.35 (March/96, station 2) to $38.47 \mathrm{mg} \cdot \mathrm{m}^{-3}$ (June/96, station 1). The average value was $9.90 \mathrm{mg} . \mathrm{m}^{-3}$. The results allowed to classify the esturay of the Jaguaribe river as a high productivity area, allowing a high phytoplankton biomass, mainly in the rainy season.

KEY WORDS: Estuary; Chlorophyll-a; Phytoplankton; Biomass. 


\section{INTRODUÇÃO}

Os estuários são corpos de águas costeiras, semi-fechados, que apresentam uma livre conexão com o mar aberto, dentro do qual, a água do mar é gradativamente diluída pela água doce proveniente da drenagem terrestre (Pritchard, 1967). Estes ambientes se caracterizam por apresentar uma alta taxa de produção primária, mostrando-se freqüentemente mais produtivos do que quaisquer massas de água salgada e doce (Odum, 1971).

Do ponto de vista ecológico, os estuários são ecossistemas, nos quais, o marco fisico-ambiental reflete uma natureza bastante dinâmica. Assim, o ecossistema estuarino é um ambiente aberto, que está dominado por processos físicos e subsídios de energia, onde existe um grande intercâmbio de materiais bióticos e abióticos com outros ecossistemas, incluindo água, sais nutrientes, sedimentos, matéria orgânica e organismos. (Yáñez-Arancibia, 1986). Além do mais, estes ecossistemas são extremamente importantes do ponto de vista econômico, uma vez que a utilização destas áreas para beneficio do homem é bastante diversificada. É nestes ambientes, que parte da população retira seus alimentos de forma racional, em atividades de aqüicultura ou explorando diretamente de forma indiscriminada. Muitos estuário são ainda locais de importante tráfego de navegação devido à existência de importantes portos ou da exploração turística do local.

No ecossistema estuarino de Itamaracá (Canal e estuários) vem sendo desenvolvidos desde a década de setenta, vários trabalhos sobre sistemática e ecologia de organismos marinhos, bem como, pesquisas para determinação dos parâmetros físico-químicos com a finalidade de se avaliar o potencial produtivo do ecossistema. Visando complementar os estudos nos diversos sistemas estuarinos, foi selecionado o estuário do rio Jaguaribe, o único que nasce ao norte da ilha e deságua no oceano, com o objetivo de se detertminar a biomassa fitoplanctônica e o grau de eutrofização do referido estuário.

\section{DESCRIÇÃO DA ÁREA}

O estuário do rio Jaguaribe, localizado na porção norte da Illha de Itamaracá, entre $07^{\circ} 43^{\prime} 08^{\prime \prime}$ à $07^{\circ} 45^{\prime} 32^{\prime \prime}$ Lat. S. e $34^{\circ} 50^{\prime} 14^{\prime \prime}$ à $34^{\circ} 51^{\prime} 05^{\prime \prime}$ Long., é o mais importante curso d'água da ilha. A sua bacia hidrográfica ocupa cerca de $18 \mathrm{~km}^{2}$ do território municipal. É formado pela junção do riacho Jacaré que nasce nas mediações da mata do Amparo e o riacho Poço de Cobre, que nasce no Morro do Giz. O rio, a partir da nascente tem direção sudeste - nordeste e percorre aproximadamente 9 (nove) $\mathrm{km}$ de extensão, desaguando no oceano Atlântico em uma área denominada Pontal do Jaguaribe (Andrade, 1955; FIDEM 1986).

Ao longo deste curso encontram-se inúmeras coroas na sua foz, que aparecem durante as baixa-mares, até área de apicuns ou salgado, no início de seu estuário, abrigando uma fauna e flora típicas dessas áreas. É na porção intermediária deste rio que se encontra um dos bancos com a maior concentração de poliquetos marinhos que já foi visto. 
$\mathrm{Na}$ margem direita, região de antigas salinas, várias famílias estão abrigadas vivendo basicamente da agricultura de subsistência e da atividade pesqueira realizada no estuário do rio e da prática de piscicultura bastante artesanal, em viveiros, procedente das citadas salinas, que são despescados uma vez ao ano. Nesta margem a ação antrópica é bastante evidente, a vegetação é composta de mangue de pequeno porte e em alguns trechos o manguezal deu lugar a construção de algumas residências. Já na margem esquerda, o manguezal tem um porte bem mais robusto, inenos degradado pelo homem ( Fig. 1).

\section{MATERIAL E MÉTODOS}

Coletas mensais foram feitas em dois regimes de marés em três estações fixas, durante o periodo de maio de 1995 à julho de 1996, utilizando-se uma lancha, Lacimar II, equipada com motor de popa de $45 \mathrm{HP}$, pertencente ao Departamento de Oceanografia da UFPE.

Foram delimitadas três estações de coleta (Fig. 1) demarcadas ao longo do estuário do rio (Estação 1, localizada à montante do estuário, aproximadamente 2,5 $\mathrm{km}$ da foz; Estação 2 localizada aproximadamente a 1,5 km da estação 1, nas mediações de uma ilhota coberta por manguezais; Estação 3 - localizada na desembocadura do rio, em uma região denominada Pontal do Jaguaribe, onde ocorre a travessia dos pedestres).

A biomassa fitoplanctônica foi determinada através do conteúdo de clorofila $a$, empregando-se a análise espectrofotométrica descrita por Thompson (1952) e modificada por Creitz e Richards (1955). Esta metodologia é também encontrada em UNESCO (1966), Strickland e Parsons (1968), Tundisi (1969), Teixeira (1973).

As amostras foram coletadas na camada superficial da água, utilizandose garrafas coletoras tipo van Dorn e transferidas para vasilhames com capacidade para um (1) litro, sendo devidamente numerados e protegidos da luz solar. $\mathrm{O}$ volume d'água coletado variou de dois a três litros em cada estação:-

Todo o material coletado foi levado imediatamente à base de Piscicultura do Departamento de Oceanografia da Universidade Federal de Pernambuco, localizada na Itha de Itamaracá, onde procedeu-se as filtrações.

No laboratório, a biomassa fitoplanctônica foi fracionada utilizando-se tela de fracionamento com abertura de malha de 20 e $50 \mu \mathrm{m}$ e filtros Millipore HA de $47 \mathrm{~mm}$ de diâmetro e $0,45 \mu \mathrm{m}$ de porosidade, permitindo assim a obtenção de frações entre 0,45 a $20 \mu \mathrm{m}$, entre 20 a 50 e maiores que $50 \mu \mathrm{m}$. O fracionamento foi feito em série, sendo as amostras filtradas primeiro através da tela com malha de $50 \mu \mathrm{m}$ e em seguida em $20 \mu \mathrm{m}$, os organismos que passaram através destas malhas foram retidos em filtros Millipore ${ }^{\circledR}$.

Os organismos retidos nas malhas, foram retirados com jatos d'água de uma pinceta contendo água local previamente filtrada, e em seguida, retidos em filtros Millipore , HA, formando as frações entre $20-50$ e maiores que $50 \mu \mathrm{m}$.

$O$ processo de filtração das amostras com os filtros Millipore ${ }^{\text {(i) }}$ foi sob vácuo, mantendo-se sempre uma pressão inferior a 0,5 atmosfera. Os filtros com o material retido, foram expostos sobre filtros de papel por alguns minutos para eliminar o excesso d'água, em seguida guardados em envelopes de papel 
contendo os dados referentes às amostras e mantidos em freezer a uma temperatura aproximada a $-18^{\circ} \mathrm{C}$, até a realização da análise espectrofotométrica.

$\mathrm{Na}$ extração da clorofila $a$, os filtros foram colocados em tubos de ensaio com capacidade de $10 \mathrm{ml}$ contendo acetona a $90 \%$ e foi empregado o procedimento de recomendado por Parsons e Strickland (1963) e UNESCO (1966).

As leituras espectrofotométricas foram realizadas em um aparelho de marca Micronal B 280, nos comprimentos de onda de 630, 645, 663, 664, 665 e 750 nanômetros (nm). A partir dos resultados obtidos nas leituras espectrofotométricas, a concentração da clorofila $a$ foi calculada aplicando-se a fórmula de Parsons e Strickland (1963). Imediatamente após as leituras espectrofotométricas para a obtenção da clorofila $\boldsymbol{a}$ total, cada amostra foi acidificada com ácido clorídrico a $1 \mathrm{~N}$ (um normal), e novas leituras foram realizadas em dois comprimentos de onda, 665 e $750 \mathrm{~nm}$, a partir destas, pode-se estimar a clorofila a ativa e seus produtos de degradação, empregando-se as equações apresentadas por Lorenzen (1967).

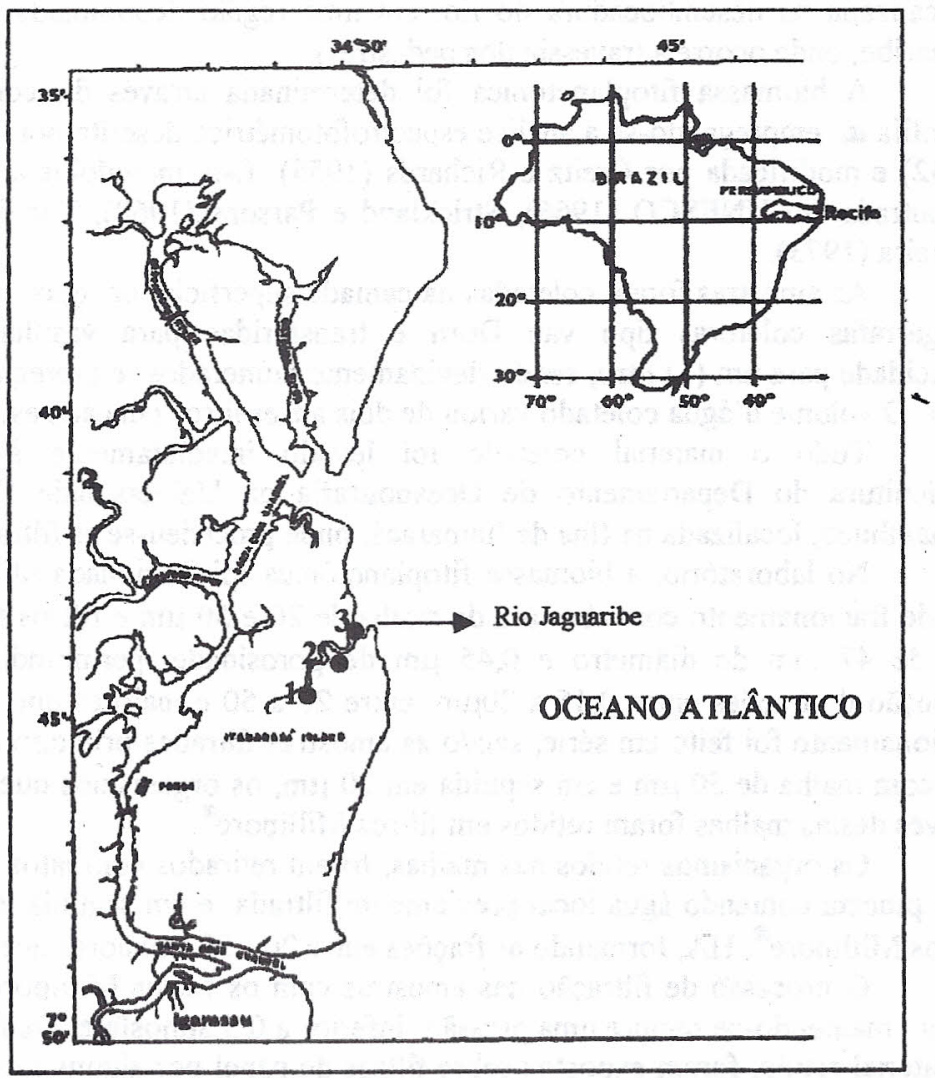

Figura 1 - Localização da área e estações de coleta. 


\section{Clorofila $a$ total}

\section{RESULTADOS}

Os valores de clorofila $a$ total registrados no estuário do rio Jaguaribe durante a baixa-mar, variaram entre $4,06 \mathrm{mg} \mathrm{m}^{-3}$ e $35,49 \mathrm{mg} \mathrm{m}^{-3}$, sendo o valor mínimo registrado no mês de setembro e o máximo em outubro/95, ambos na estação 2. O valor médio neste regime de maré foi de $13,04 \mathrm{mg} \mathrm{m}^{-3}, \mathrm{Em}$ preamar, os valores variaram entre $1,35 \mathrm{mg} \mathrm{m}^{-3}$ e $38,47 \mathrm{mg} \mathrm{m}^{-3}$, sendo o menor valor registrado em março/96 na estação 2 e o maior em junho/96, na estação 1 . $O$ valor médio em regime de preamar foi $9,90 \mathrm{mg} \mathrm{m}^{-3}$ (Figura 2, Tabelas 2 à 3).

Os índices de clorofila $a$ total registrados na estação 1 durante a baixamar oscilaram entre $7,19 \mathrm{mg} \mathrm{m}^{-3}$ e $25,48 \mathrm{mg} \mathrm{m}^{-3}$. O menor valor ocorreu em agosto e setembro/95 e o maior em maio/95. O valor médio nesta estação foi de $13,21 \mathrm{mg} \mathrm{m}^{-3}$. Em preamar, o valor mínimo foi de $2,61 \mathrm{mg} \mathrm{m}^{-3}$, obtido em janeiro/96, e o máximo, $38,47 \mathrm{mg} \mathrm{m}^{-3}$, que ocorreu no mês de junho também em 1996. A média dos valores neste regime foi de $9,66 \mathrm{mg} \mathrm{m}^{-3}$.

$\mathrm{Na}$ estação 2, os valores mínimo e máximo registrados durante a baixamar foram respectivamente $4,06 \mathrm{mg} \mathrm{m}^{-3}$ e $35,49 \mathrm{mg} \mathrm{m}^{-3}$, obtidos nos meses de setembro e outubro/95. Nesta estação foram observados o menor e o maior valor para o ecossistema durante o regime de baixa-mar. A média dos valores foi de $15,50 \mathrm{mg} \mathrm{m}^{-3}$. Em preamar, foi obtido o mínimo de $1,35 \mathrm{mg} \mathrm{m}^{-3}$ e o máximo de $31,15 \mathrm{mg} \mathrm{m}^{-3}$, os quais ocorreram, respectivamente, nos meses de março/96 e julho/ 95 , sendo registrado um índice médio de $10,29 \mathrm{mg} \mathrm{m}^{-3}$.

Para a estação 3, foram registrados, em baixa-mar, as concentrações mínima e máxima de $4,36 \mathrm{mg} \mathrm{m}^{-3}$ e $29,25 \mathrm{mg} \mathrm{m}^{-3}$, obtidas, respectivamente, nos meses de outubro e junho/95 e um valor médio de $10,40 \mathrm{mg} \mathrm{m}^{-3}$. Em preamar, estes índices foram de $1,75 \mathrm{mg} \mathrm{m}^{-3}$ a $27,95 \mathrm{mg} \mathrm{m}^{-3}$ e ocorreram nos meses de outubro/95 e junho/96. O valor médio para este regime foi $9,74 \mathrm{mg} \mathrm{m}^{-3}$.

Fração entre 0,45 e $20 \mu \mathrm{m}$

No que diz respeito ao fracionamento os valores de clorofila $a$ correspondentes a fração do fitoplâncton entre 0,45 e $20 \mu \mathrm{m}$ registrados durante a baixa-mar variaram entre $2,92 \mathrm{mg} \mathrm{m}$ e $32,19 \mathrm{mg} \mathrm{m}^{-3}$, os valores mínimo e máximo foram observados no mês outubro de 1996 nas estações 1 e 2, respectivamente, eqüivalendo a $66,97 \%$ e $90,70 \%$ do fitoplâncton total. Em preamar, esta fração apresentou valores mínimo e máximo de $0,78 \mathrm{mg} \mathrm{m}^{-3}$ e $34,85 \mathrm{mg} \mathrm{m}^{-3}$, os quais ocorreram no meses de março/96, na estação 2 , e de junho/96, na estação 1, e corresponderam respectivamente a $57,78 \%$ e $90.59 \%$ (Figura 2, Tabelas 1 à 3).

$\mathrm{Na}$ estação 1, esta fração em baixa-mar oscilou entre $6,16 \mathrm{mg} \mathrm{m}^{-3} \mathrm{e}$ $18,69 \mathrm{mg} \mathrm{m}^{-3}$, com os valores mínimo e máximo registrados nos meses de setembro e maio/95, cujos valores representaram percentuais de $85,67 \%$ e $73,35 \%$ da clorofila total. A média para este regime de maré foi de $10,52 \mathrm{mg} \mathrm{m}^{-3}$ $(80,65 \%)$. Enquanto que em preamar os valores mínimo e máximo obtidos foram $1,50 \mathrm{mg} \mathrm{m}^{-3}$ e $34,85 \mathrm{mg} \mathrm{m}^{-3}$ e ocorreram nos meses de janeiro e junho/96, 
eqüivalendo a $57,47 \%$ e $90,5985 \%$ desta fração. A média para este regime de maré foi de $7,49 \mathrm{mg} \mathrm{m}^{-3}(77,13 \%)$.

$\mathrm{Na}$ estação 2, durante a baixa-mar o teor de clorofila desta fração ficou entre $2,93 \mathrm{mg} \mathrm{m}^{-3}$ e $32,19 \mathrm{mg} \mathrm{m} \mathrm{m}^{-3}$, sendo o valor mínimo obtido em setembro/95 e o máximo no mês subsequente, os percentuais correspondentes a estes valores foram de $72,17 \%$ e $90,70 \%$. A média para este regime de maré foi de $12,53 \mathrm{mg} \mathrm{m}^{-3}(79,36 \%)$. Em preamar, os valores mínimo e máximo foram $0,78 \mathrm{mg} \mathrm{m}^{-3}$ e $22,19 \mathrm{mg} \mathrm{m}^{-3}$, sendo registrado o valor mínimo em março/96 e o máximo em julho/95, e corresponderam a $57,78 \%$ e $70,42 \%$. A média para este regime de maré foi de $7,33 \mathrm{mg} \mathrm{m}^{-3}(70,52 \%)$.

0 menor índice de clorofila $a$ desta fração na estação $3 \mathrm{em}$ baixa-mar foi $2,92 \mathrm{mg} \mathrm{m}^{-3}$ e o máximo foi $22,48 \mathrm{mg} \mathrm{m}^{-3}$ e corresponderam a $66,97 \%$ e $76,85 \%$, registrados respectivamente nos meses de outubro e junho/95. A média para este regime de maré foi de $9,15 \mathrm{mg} \mathrm{m}^{-3}(76,08 \%)$. Em preamar, os registros mínimo e máximo foram, respectivamente, $1,28 \mathrm{mg} \mathrm{m}^{-3}$ obtido em outubro/95, e $22,03 \mathrm{mg} \mathrm{m}^{-3}$ obtido em julho/95 e eqüivalendo a $73,14 \%$ e $79,47 \%$. A média para este regime de maré foi de $6,88 \mathrm{mg} \mathrm{m}^{-3}(67,11 \%)$.

Fração entre 0,20 e $50 \mu \mathrm{m}$

Os valores da concentração de clorofila $a$ da fração entre 0,20 e $50 \mu \mathrm{m}$ durante a baixa-mar variaram entre $0,45 \mathrm{mg} \mathrm{m}^{-3}$ e $4,05 \mathrm{mg} \mathrm{m}^{-3}$ e correspondem a $6,26 \%$ e $17,00 \%$, sendo o valor mínimo registrado em setembro/95 na estação-1 e o máximo em junho/95 na estação 2 . Em preamar as concentrações mínima e máxima foram $0,32 \mathrm{mg} \mathrm{m}^{-3}$ e $6,75 \mathrm{mg} \mathrm{m}^{-3}$, obtidos nos meses de outubro/95 na estação 3 e em julho/95 na estação 2 , corresponderam a $18,29 \%$ e $21,42 \%$ (Figura 22, Tabelas 19 a 21).

$\mathrm{Na}$ estação 1, durante a baixa-mar, o menor índice foi $0,45 \mathrm{mg} \mathrm{m}^{-3} \mathrm{e}$ ocorreu no mês de setembro/95, e o maior foi $3,36 \mathrm{mg} \mathrm{m}^{-3}$ registrado no mês de junho/96 e corresponderam a $6,26 \%$ e $26,31 \%$ da clorofila total. A média para este regime de maré foi de $1,77 \mathrm{mg} \mathrm{m}^{-3}(13,29 \%)$. Em preamar, os valores mínimo e máximo foram $0,39 \mathrm{mg} \mathrm{m}^{-3}$ e $4,93 \mathrm{mg} \mathrm{m}^{-3}$, os quais, eqüivaleram a $9,95 \%$ e $23,08 \%$, sendo registrados respectivamente nos meses de abril/96 e junho/95. A média para este regime de maré foi de $1,43 \mathrm{mg} \mathrm{m}^{-3}(18,44 \%)$.

$\mathrm{Na}$ estação 2, durante a baixa-mar, o teor de clorofila desta fração oscilou entre $0,55 \mathrm{mg} \mathrm{m}$ e $4,05 \mathrm{mg} \mathrm{m}^{-3}$, eqüivalentes a $13,55 \%$ e $17,00 \%$, sendo o valor mínimo e máximo registrados nos meses de janeiro/96 e julho/95. A média para este regime de maré foi de $1,92 \mathrm{mg} \mathrm{m}^{-3}(14,09 \%)$. Em preamar variaram entre $0,41 \mathrm{mg} \mathrm{m}^{-3}$ e $6,75 \mathrm{mg} \mathrm{m}^{-3}$, os quais corresponderam a $14,34 \% \mathrm{e}$ $21,42 \%$, sendo os valores mínimos e máximos registrados, respectivamente, nos meses de janeiro/96 e julho/95. A média para este regime de maré foi de 2,06 mg $\mathrm{m}^{-3}(20,14 \%)$.

O menor teor de clorofila encontrado na estação 3 durante a baixa-mar foi de $0,59 \mathrm{mg} \mathrm{m}^{-3}$ registrado em setembro/95 e o maior, $3,41 \mathrm{mg} \mathrm{m}^{-3}$, ocorreu em junho/95, correspondendo, respectivamente, a 13,08\% e $11,06 \%$. A média para este regime de maré foi de $1,87 \mathrm{mg} \mathrm{m} \mathrm{m}^{-3}$ (17,98\%). Enquanto que em 
preamar estes valores foram $0,32 \mathrm{mg} \mathrm{m} \mathrm{m}^{-3}$ e $5,81 \mathrm{mg} \mathrm{m} \mathrm{m}^{-3}$, sendo obtidos nos meses de outubro/95 e junho/96. correspondendo a percentuais de $18,29 \%$ e $20,79 \%$ respectivamente. A média para este regime de maré foi de $1,88 \mathrm{mg} \mathrm{m}^{-3}$ $(20,71 \%)$.

\section{Fração maior que $50 \mu \mathrm{m}$}

Os teores de clorofila $a$ da fração do fitoplâncton maior que $50 \mu \mathrm{m}$, durante a baixa-mar, variaram de $0,14 \mathrm{mg} \mathrm{m}^{-3}$ a $4,65 \mathrm{mg} \mathrm{m}^{-3}$ e corresponderam a $1,95 \%$ e $15,22 \%$ da clorofila a total, sendo o valor mínimo registrado no mês de agosto/95 na estação 1, e o máximo em maio/95 na estação 2. Em preamar, a concentração mínima foi $0,15 \mathrm{mg} \mathrm{m}^{-3}$, este valor ocorreu nas três estações em diferentes meses (respectivamente, maio/95, março/96 e outubro/95) correspondendo a $2,31 \% ; 11,11 \%$ e $8,57 \%$. A máxima foi de $3,98 \mathrm{mg} \mathrm{m}^{-3}$, eqüivalendo a $18,63 \%$, obtida no mês de junho/95 na estação 1 (Figura 2 , Tabelas 1 à 3).

$\mathrm{Na}$ estação 1, durante a baixa-mar, os valores mínimo e máximo registrados foram $0,14 \mathrm{mg} \mathrm{m}^{-3}$ e $3,63 \mathrm{mg} \mathrm{m}^{-3}$ e corresponderam a $1,95 \%$ e $14,25 \%$, sendo obtidos, respectivamente, nos meses de agosto e maio/95. A média para este regime de maré foi de $0,93 \mathrm{mg} \mathrm{m}^{-3}(6,06 \%)$. Em preamar, estes valores foram $0,15 \mathrm{mg} \mathrm{m}^{-3}$ e $3,98 \mathrm{mg} \mathrm{m}^{-3}$, obtidos nos meses de maio e junho/95 e corresponderam, respectivamente, a $2,31 \%$ e $18,63 \%$ desta fração. A média para este regime de maré foi de $0,75 \mathrm{mg} \mathrm{m}^{-3}(9,42 \%)$.

$\mathrm{Na}$ estação 2, em baixa-mar, a concentração mínima foi $0,20 \mathrm{mg} \mathrm{m}^{-3}$ em junho/96 e a máxima $4,65 \mathrm{mg} \mathrm{m}^{-3}$ no mês de maio/95, corresponderam a $1,36 \%$ e $15,22 \%$. A média para este regime de maré foi de $1,05 \mathrm{mg} \mathrm{m}^{-3}(6,55 \%)$. Em preamar, estes índices foram $0,15 \mathrm{mg} \mathrm{m}^{-3}$ e $2,57 \mathrm{mg} \mathrm{m}^{-3}$, registrados nos meses de março/96 e julho/95 e corresponderam a $11,11 \%$ e $8,16 \%$. A média para este regime de maré foi de $0,90 \mathrm{mg} \mathrm{m}^{-3}(9,33 \%)$.

$\mathrm{Na}$ estação 3, as concentraç̃̃es mínima e máxima, durante a baixa-mar, foram $0,15 \mathrm{mg} \mathrm{m}^{-3}$ e $3,46 \mathrm{mg} \mathrm{m}^{-3}$, registradas respectivamente nos meses de março/96 e maio/95 e corresponderam a $1,54 \%$ e $13,4 \%$. A média para este regime de maré foi de $0,88 \mathrm{mg} \mathrm{m}^{-3}(9,33 \%)$. Enquanto que em preamar estas concentrações foram $0,15 \mathrm{mg} \mathrm{m}^{-3}$ e $3,25 \mathrm{mg} \mathrm{m}^{-3}$ sendo obtidas nos meses de outubro/95 e junho/95. Estes valores corresponderam a $8,57 \%$ e $16,35 \%$ da clorofila. A média para este regime de maré foi de $0,99 \mathrm{mg} \mathrm{m}^{-3}(12,18 \%)$. 
Estação 1
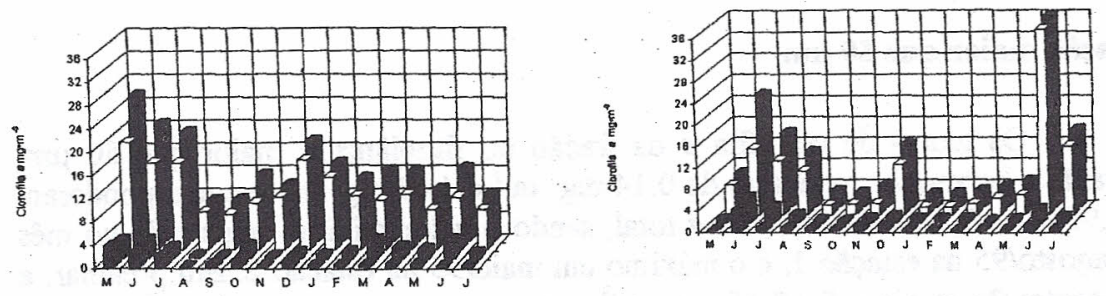

Estação 2
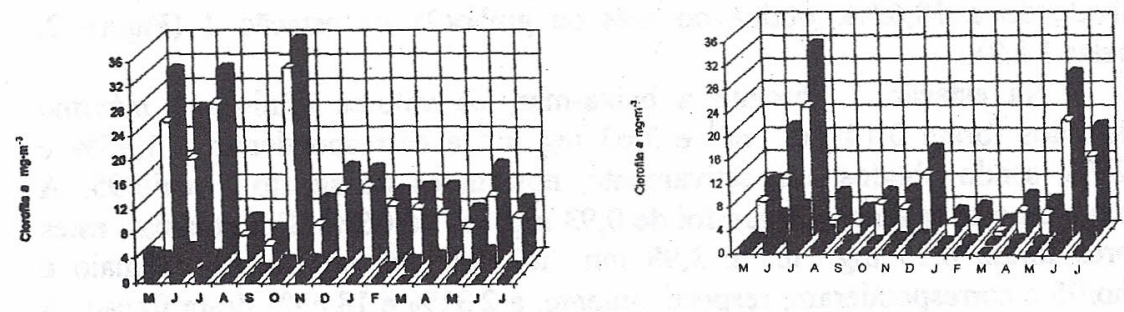

\section{Estação 3}
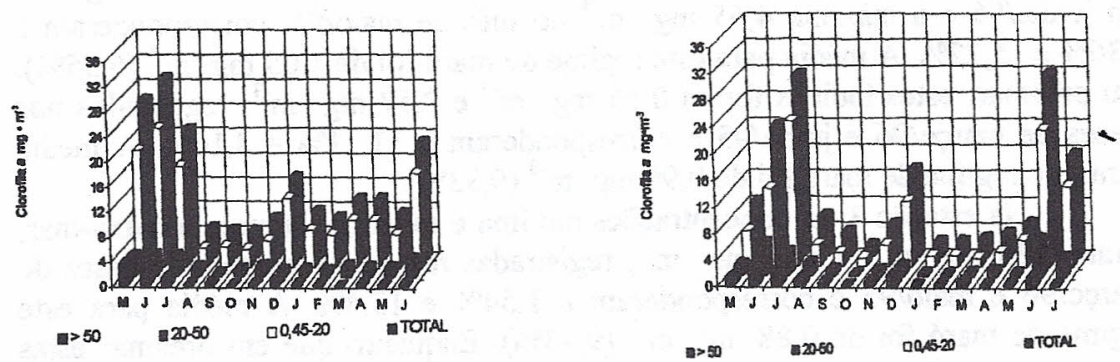

FIGURA 2 - Variação sazonal da biomassa fitoplanctônica $\left(\mathrm{mg} \cdot \mathrm{m}^{-3}\right)$ no estuário do rio Jaguaribe, Itamaracá, Pernambuco, no período de maio/95 a julho/96. 
Tabela 1 - Variação sazonal da biomassa fitoplanctônica (mg. Clor. $a \cdot \mathrm{m}^{-3}$ ) da estação 01, no estuário do rio Jaguaribe, Itamaracá, Pernambuco. BM=baixa-mar, PM=preamar

\begin{tabular}{|c|c|c|c|c|c|c|c|c|c|c|c|c|c|c|}
\hline \multirow{4}{*}{ MESES } & \multicolumn{14}{|c|}{ FRA $\mathcal{A} \cap O(\mu \mathrm{m})$} \\
\hline & \multicolumn{4}{|c|}{$0,45<20$} & \multicolumn{4}{|c|}{$20>50$} & \multicolumn{4}{|c|}{$>\mathbf{5 0}$} & \multicolumn{2}{|c|}{ TOTAL } \\
\hline & \multicolumn{2}{|c|}{$\overline{\mathbf{B M}}$} & \multicolumn{2}{|c|}{$\mathbf{P M}$} & \multicolumn{2}{|c|}{$\mathbf{B M}$} & \multicolumn{2}{|c|}{$\mathbf{P M}$} & \multicolumn{2}{|c|}{$\mathbf{B M}$} & \multicolumn{2}{|c|}{$\mathbf{P M}$} & \multirow{2}{*}{$\begin{array}{c}\mathrm{BM} \\
\mathrm{mg}^{-3} \\
\mathrm{~m}^{-3}\end{array}$} & \multirow{2}{*}{$\begin{array}{c}\mathrm{PM} \\
\mathrm{mg} \cdot \\
\mathrm{m}^{-3}\end{array}$} \\
\hline & $\begin{array}{l}\mathrm{mg} \\
\mathbf{m}^{-3}\end{array}$ & $\%$ & $\begin{array}{c}\mathrm{mg} \\
\mathrm{m}^{-3}\end{array}$ & $\%$ & $\begin{array}{l}\mathrm{mg} . \\
\mathrm{ma}^{-3}\end{array}$ & $\%$ & $\begin{array}{l}\mathbf{m g}^{-3} \\
\mathbf{m}^{-3}\end{array}$ & $\%$ & $\begin{array}{l}\text { mg. } \\
\text { m }^{-3}\end{array}$ & $\%$ & $\begin{array}{l}\mathrm{mg} . \\
\mathrm{ma}^{-3}\end{array}$ & $\%$ & & \\
\hline Hidater & 18,69 & 3,35 & 5,68 & 7,65 & 3,16 &, 40 & 0,65 & 10,03 & 3,63 & 14,25 & 0,15 & 2,31 & 25,48 & 6,48 \\
\hline Jun. & 15,04 & 73,40 & 12,45 & 58,29 & 3,20 & 15,62 & & & 2,25 & & 98 & 18,63 & 20,49 & 21,36 \\
\hline Jul. & 15,03 & 79,23 & 10,26 & 72,77 & $I_{8}$ & 10,44 & & & 96 & & & & 18,97 & 4,10 \\
\hline $\mathrm{Ag}$ & & 91,10 & & 78, & & 6,95 & & & 14 & 1,95 & 60 & 5,72 & 7,19 & 10,48 \\
\hline Set. & 6 & 85,67 & 1,86 & 60,78 & 0,45 & 6,26 & 0,66 & 21,57 & 0,58 & 8,07 & 0,54 & 17,65 & 7,19 & 3,06 \\
\hline Out. & 8,12 & 69,82 & 2,04 & 73,91 & 2,32 & 19,95 & 0,40 & 14,49 & 1,19 & 10,23 & 0,32 & 11,59 & 11,63 & 2,76 \\
\hline Nov. & 9,13 & 92,41 & 2,24 & 53,72 & 0,47 & 4,76 & 0,99 & 23,74 & 0,28 & 2,83 & 0,94 & 22,54 & 9,88 & 4,17 \\
\hline Dez. & 15,57 & 88,77 & 9,55 & 80,32 & 1,1 & 6,33 & 1,37 & & 0,86 & 4,90 & 0,97 & 8,16 & 17,54 & 11,89 \\
\hline $\operatorname{Jan} / 9$ & 12,68 & 92,62 & & & & 75 & & & 86 & 63 & 6 & 6 & 3,69 & 2,61 \\
\hline Fev. & 9,40 & 84,53 & 1,52 & 56,93 & 1,26 & 11,33 & 0,86 & 32 & 46 & 4,14 & 0,29 & 10,86 & 11,12 & 2,67 \\
\hline Mar. & 8,61 & 69,49 & 2,13 & 64,74 & 3,34 & 26,93 & 0,92 & 27,96 & 0,44 & 3,55 & 0,24 & 7,29 & 12,39 & 3,29 \\
\hline Abr. & 9,62 & 78,66 & 3,20 & 81,63 & 2,04 & 16,68 & 0,39 & 9,95 & 0,57 & 4,66 & 0,33 & 8,42 & 12,23 & 3,92 \\
\hline Maio & 7,00 & 75,67 & 3,83 & 76,45 & 1,71 & 18,49 & 0,85 & 16,97 & 0,54 & 5,84 & 0,33 & 6,59 & 9,25 & 5,01 \\
\hline Jun. & 9,15 & 71,65 & 34,85 & 90,59 & 3,36 & 26,31 & 2,65 & 6,89 & 0,26 & 2,04 & 0,97 & 2,52 & 12,77 & 38,47 \\
\hline Jul & 7,00 & 83,43 & 12,96 & 88,10 & 1,02 & 12,16 & & & 37 & 4,41 & 0,54 &, 67 & 8,39 & 14,71 \\
\hline Média & 10,52 & 80,65 & 7,49 & 77,13 & 1,77 & 13,29 & 1,43 & 18,44 & 0,93 & 6,06 & 0,75 & 9,42 & 13,21 & 9,66 \\
\hline$\sigma$ & 3,90 & 8,30 & 8,62 & 8,62 & 1,10 & 7,28 & 1,23 & 8,47 & 0,97 & 3,80 & 0,94 & 6,02 & 5,26 & 9,79 \\
\hline
\end{tabular}

Tabela 2 - Variação sazonal da biomassa fitoplanctônica (mg. Clor. $a \cdot \mathrm{m}^{-3}$ ) da estação 02 , no estuário do rio Jaguaribe, Itamaracá, Pernambuco. BM=baixa-mar, PM=preamar

\begin{tabular}{|c|c|c|c|c|c|c|c|c|c|c|c|c|c|c|}
\hline \multirow{4}{*}{ MESES } & \multicolumn{14}{|c|}{ FRACAO $(\mu \mathrm{m})$} \\
\hline & \multicolumn{4}{|c|}{$0,45<20$} & \multicolumn{4}{|c|}{$20>50$} & \multicolumn{4}{|c|}{$>50$} & \multicolumn{2}{|c|}{ TOTAL } \\
\hline & \multicolumn{2}{|c|}{$\mathrm{BM}$} & \multicolumn{2}{|c|}{$\mathbf{P M}$} & \multicolumn{2}{|c|}{$\mathbf{B M}$} & \multicolumn{2}{|c|}{$\mathbf{P M}$} & \multicolumn{2}{|c|}{$\mathbf{B M}$} & \multicolumn{2}{|c|}{$\mathbf{P M}$} & \multirow{2}{*}{$\begin{array}{c}\mathrm{BM} \\
\mathrm{mg}^{-3} \\
\mathrm{~m}^{-3}\end{array}$} & \multirow{2}{*}{$\begin{array}{c}\mathbf{P M} \\
\underset{\mathrm{mg}}{\mathrm{m}^{-3}}\end{array}$} \\
\hline & $\begin{array}{l}\mathrm{mg} . \\
\mathrm{m}^{-3}\end{array}$ & $\%$ & \begin{tabular}{|c|c|}
$\mathrm{mg}^{-3}$ \\
$\mathrm{~m}^{-3}$
\end{tabular} & $\%$ & $\begin{array}{c}\mathrm{mg}^{-3} \\
\mathrm{~m}^{-3} \\
\end{array}$ & $\%$ & $\begin{array}{l}\mathbf{m g}_{-} \\
\mathbf{m}^{-3}\end{array}$ & $\%$ & $\begin{array}{l}\mathrm{mg}^{-3} \\
\mathrm{~m}^{-3}\end{array}$ & $\%$ & $\begin{array}{l}\text { mg. } \\
\mathbf{m g}^{-3}\end{array}$ & $\%$ & & \\
\hline Maio/95 & 23,33 & 76,37 & 5,78 & 72,70 & 2,57 & 8,41 & 1,01 & 12,70 & 4,65 & 15,22 & 1,16 & 14,59 & 30,55 & 7,95 \\
\hline Jun. & 17,09 & 71,72 & 9,78 & 56,37 & 4,05 & 17,00 & 5,25 & 30,26 & 2,69 & 11,29 & 2,32 & 13,37 & 23,83 & 17,35 \\
\hline Jul. & 26,24 & 85,56 & 22,19 & 70,42 & 2,76 & 9,00 & 6,75 & 21,42 & 1,67 & 5,45 & 2,57 & 8,16 & 30,67 & 31,15 \\
\hline Aga & 4,53 & 76,13 & 2,63 & 43,91 & 1,05 & 17,65 & 2,40 & 40,07 & 0,37 & 6,22 & 0,96 & 6,03 & 5,95 & 5,99 \\
\hline Set. & 2,93 & 72,17 & 2,10 & 66,25 & 0,55 & 13,55 & 0,73 & 23,03 & 0,58 & 14,29 & 0,34 & 10,73 & 4,06 & 3,17 \\
\hline Out. & 32,19 & 90,70 & 5,44 & 90,07 & 1,88 & 5,30 & 0,46 & 6,62 & 1,42 & 4,00 & 0,20 & 3,31 & 35,49 & 6,04 \\
\hline Nov. & 6,26 & 68,57 & 4,64 & 71,49 & 1,99 & 21,80 & 1,26 & 19,41 & 0,88 & 9,64 & 0,59 & 9,09 & 9,13 & 6,49 \\
\hline Dez & 12,03 & 83,66 & 10,41 & 77,23 & 1,43 & 9,94 & 1,59 & 11,80 & 0,92 & 6,40 & 1,48 & 10,98 & 14,38 & 13,48 \\
\hline $\mathrm{Jan} / 96$ & 12,47 & 88,44 & 2,18 & 76,22 & 1,30 & 9,22 & 0,41 & 14,34 & 0,33 & 2,34 & 0,27 & 9,44 & 14,10 & 2,86 \\
\hline Fev. & 9,46 & 89,25 & 2,48 & 67,76 & 0,76 & 7,17 & 0,78 & 21,31 & 0,38 & 3,58 & 0,40 & 10,93 & 10,60 & 3,66 \\
\hline Mar. & 8,94 & 80,40 & 0,78 & 57,78 & 1,95 & 17,54 & 0,42 & 31,11 & 0,23 & 2,07 & 0,15 & 11,11 & 11,12 & 1,35 \\
\hline Abr. & 8,04 & 71,34 & 4,30 & 77,48 & 2,80 & 24,84 & 0,93 & 16,76 & 0,43 & 3,82 & 0,32 & $\mathbf{5 , 7 7}$ & 11,27 & $\mathbf{5 , 5 5}$ \\
\hline Maio & 5,81 & 77,16 & 3,68 & 77,97 & 1,16 & 15,41 & 0,75 & 15,89 & 0,56 & 7,44 & 0,29 & 6,14 & 7,53 & 4,72 \\
\hline Jun. & 11,00 & 74,58 & 19,81 & 74,19 & 3,55 & 24,07 & 4,85 & 18,16 & 0,20 & 1,36 & 2,04 & 7,64 & 14,75 & 26,70 \\
\hline Jul & 7,62 & 84,39 & 13,71 & 77,99 & 0,94 & 10,41 & 3,39 & 19,28 & 0,47 & 5,20 & 0,48 & 2,73 & 9,03 & 17,58 \\
\hline Médlia & 12,53 & 79,36 & 7,33 & 70,52 & 1,92 & 14,09 & 2,06 & 20,14 & 1,05 & 6,55 & 0,90 & 9,33 & 15,50 & 10,29 \\
\hline$\sigma$ & 8,54 & 7,22 & 6,61 & 11,13 & 1,04 & 6,25 & 2,04 & 8,48 & 1,20 & 4,30 & 0,82 & 3,84 & 9,85 & 9,15 \\
\hline
\end{tabular}


Tabela 3 - Variação sazonal da biomassa fitoplanctônica (mg. Clor. $\boldsymbol{a} \cdot \mathrm{m}^{-3}$ ) da estação 03 , no cstuário do rio Jaguaribc, Itamaracá, Pcrnambuco. BM=baixa-mar, PM=prcamar

\begin{tabular}{|c|c|c|c|c|c|c|c|c|c|c|c|c|c|c|}
\hline \multirow{4}{*}{ MESES } & \multicolumn{14}{|c|}{ F R A C Ã O ( $(\mu \mathrm{m})$} \\
\hline & \multicolumn{4}{|c|}{$0,45<20$} & \multicolumn{4}{|c|}{$20>50$} & \multicolumn{4}{|c|}{$>50$} & \multicolumn{2}{|c|}{ TOTAL } \\
\hline & \multicolumn{2}{|c|}{$\mathbf{B M}$} & \multicolumn{2}{|c|}{$\mathbf{P M}$} & \multicolumn{2}{|c|}{$\mathbf{B M}$} & \multicolumn{2}{|c|}{$\mathbf{P M}$} & \multicolumn{2}{|c|}{$\mathbf{B M}$} & \multicolumn{2}{|c|}{$\mathbf{P M}$} & \multirow{2}{*}{$\frac{\mathrm{BM}}{\mathrm{mg}_{-3} \mathrm{~m}}$} & \multirow{2}{*}{$\frac{\overline{\mathbf{P M}}}{\mathrm{mg}^{-3}}$} \\
\hline & $\underset{\mathbf{m}^{-3}}{\mathrm{mg}}$ & $\%$ & $\mathrm{mg}_{\mathbf{m}^{-3}}$ & $\%$ & $\mathrm{mg}^{-3}$ & $\%$ & $\mathrm{mg}_{\mathrm{m}^{-3}}$ & $\%$ & $\mathrm{mg}_{\mathrm{m}^{-3}}$ & $\%$ & $\mathrm{mg}_{\mathbf{m}^{-3}}$ & $\%$ & & \\
\hline Maio/95 & 18,90 & 7 & 5,30 & 3 & 3,33 & 12,96 & 1,67 & 4 & 3,46 & 77 & 1,32 & 5,92 & 25,69 & 8,25 \\
\hline Jun. & 2,48 & 6,85 & 11,77 & 59,21 & 3,41 & 11,66 & 4,86 & 24,45 & 3,36 & 11,49 & 3,25 & 16,35 & 29,25 & 19,88 \\
\hline Jul. & 31 & 8.85 & 22,03 & & 3,31 & 15,80 & 3,55 & & 1,33 & 6,35 & 2,14 & 7,72 & 20,95 & 27,72 \\
\hline Ag & 1 & 64,26 & 3,19 & 7 & 1,52 & 31,40 & 2,03 & 32,69 & 0,21 & 4,34 & 99 & 15,94 & 4,84 & 6,21 \\
\hline Set & & 73 & 2,07 & 0 & 0,5 & 3,08 & 1,07 & 8,69 & 64 &, 19 & 59 & 2 & 4,51 & 3,73 \\
\hline O & & 7 & 1,2 & & 12 & 7,75 & 0,32 & 29 & 23 & 28 & 15 & 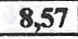 & 4,36 & 1,75 \\
\hline No & 1 & 1 & 3,23 & 8 & 1,80 & 27,69 & 0,91 & 18,42 & 39 & 00 & 80 & 5,19 & 6,50 & 4,94 \\
\hline Dez & 17 & 84,88 & 9,95 & 31 & 1,11 & 8,43 & 1,66 & 12,40 & 0,88 & 6,69 & 78 & 13,29 & 13,16 & 13,39 \\
\hline $\operatorname{Jan} / 9$ & & 78,14 & 1,66 & 71,86 & 1,27 & 16,62 & 0,49 & 21,21 & 0,40 & 5,24 & 0,16 & 6,93 & 7,64 & 2,31 \\
\hline Fev. & & 79,58 & 1,70 & & 1,09 & 16,37 & 0,40 & & 0,27 & 4,05 & 0,30 & 0 & 6,66 & 2,40 \\
\hline $\mathbf{M}$ & 3 &, 53 & 1,35 & & 1,8 & 18,93 & 0,70 & & 0,15 & 54 & 86 & 29,55 & 9,72 & 2,91 \\
\hline & 4 & 36 & 2,31 & & 1,64 & 00 & 1,02 & 79 & 0,53 & 82 & 34 & 0 & 9,11 & 3,67 \\
\hline Maio & & 72,52 & 4,15 & & 1,63 & 35 & 0,68 & & 0,42 & 63 & 38 & 7,29 & 7,46 & 5,91 \\
\hline Jun. & 15,13 & 81,24 & 20,84 & 74,56 & 3,13 & 16,59 & 5,81 & 20,79 & 0,61 & 3,23 & 1,30 & 4,65 & 18,87 & 27,95 \\
\hline Jul & 7,38 & 82,92 & 12,34 & 78,15 & 1,12 & 12,58 & 3,03 & 19,19 & 0,40 & 4,49 & 0,42 & 2,66 & 8,90 & 15,75 \\
\hline Mé & 9,15 & 76,08 & 6,88 & & 1,87 & 17,98 & 1,88 & 20,71 & 0,88 & 6,52 & 0,99 & 12,18 & 10,40 & 9,74 \\
\hline$\sigma$ & 6,24 & 6,50 & 6,99 & 10,41 & 0,95 & 6,58 & 1,70 & 5,99 & 1,07 & 3,66 & 0,86 & 6,65 & 6,50 & 9,09 \\
\hline
\end{tabular}

\section{DISCUSSÃO E CONCLUSÃO}

A determinação da biomassa fitoplanctônica através da clorofila $a$ é um dos métodos mais precisos que possibilita a avaliação da comunidade dos produtores primários aquáticos. Em Pernambuco, estudos desta natureza vem sendo realizados em vários estuários e também em regiões costeiras.

As variações sazonais da biomassa fitoplanctônica tendem a seguir um padrão que varia de acordo com a latitude. Nas regiões polares, existe um único pico do fitoplâncton no início do verão, onde a densidade populacional pode ser centenas de vezes maior que a do inverno. Em regiões temperadas, ocorre um pico na primavera, seguido por um declínio no verão e normalmente por um pico secundário no outono. Em mares tropicais, normalmente ocorrem pequenas oscilações, as quais podem aumentar em torno de cinco vezes a densidade populacional. No entanto, fatores que limitam estes padrões são muitos e as interações são complexas (Fogg, 1975).

Em ambientes estuarinos, as variações sazonais que ocorrem em alguns fatores ambientais estão relacionadas com fatores climatológicos como precipitação pluviométrica, radiação solar e movimentos sazonais da água, como a circulação local e influência de correntes costeiras pela ação dos ventos (Tundisi, 1970).

Flutuações sazonais de densidade, biomassa e produção fitoplanctônica, em estuários e áreas costeiras do Brasil, têm sido freqüentemente associado à precipitação pluviométrica. Acredita-se que o carreamento de nutrientes para estas áreas pela drenagem terrestre, contribui significativamente para o aumento das concentrações dos mesmos, favorecendo a comunidade fitoplanctônica. Segundo Eskinazi-Leça (1990) e 
Eskinazi-Leça et al. (1993), as variações na produção fitoplanctônica ainda apresentam um padrão anual que depende da ação dos fatores locais, onde em áreas sujeitas a grandes aportes terrígenos de material em suspensão, há florescimento do fitoplâncton no período seco, enquanto que, em locais com leve influência terrígena, isto se verifica no período chuvoso.

Este padrão no ciclo anual já foi constatado em vários estuários no estado de Pernambuco e em outras áreas costeiras, como por exemplo, na Bacia do Pina, Feitosa (1988); Feitosa \& Passavante (1990), evidenciaram um ciclo sazonal bem definido da biomassa fitoplanctônica (clorofila $a$ ), com valores elevados durante a primavera-verão e valores mais baixos no período de outono-inverno. Resultados semelhantes foram registrados por Travassos (1991), no estuário do rio Capibaribe (PE) os baixos valores da concentração de clorofila $\boldsymbol{a}$ durante o período de maior intensidade pluviométrica são associados à diminuição do poder de penetração da luz devido o aumento do material em suspensão resultantes da drenagem terrestre.

Resurreição (1990), estudando a biomassa fitoplanctômica da plataforma continental de Pernambuco, afirma que a precipitação pluviométrica colntribuiu como fator de inibição da concentração de clorofila a nas estações mais próximas da costa, enquanto que, nas estações mais afastadas, verificou-se uma correlação positiva entre precipitação e biomassa do fitoplâncton, com uma contribuição das chuvas para o incremento do teor de clorofila. Enquanto que para Maceno-Silva e Brandini (1990), estudando a composição e distribuição da biomassa fitoplanctônica na plataforma continental do Estado de Santa Catarina, encontraram máximos de clorofila nas estações costeiras decrescendo em direção as oceânicas.

Moura (1992), estudando a variação sazonal do estuário do Paraíba do Norte, encontrou resultados semelhantes, chamando a atenção para o fato de que esta variabilidade pode explicar as variações observadas nos teores de clorofila $a$ e produção primária e cita vários autores os quais têm demonstrado que as variações diumas observadas na produção primária estão relacionadas com a radiação solar, nutrientes, concentração de pigmentos fotossintéticos e composição das espécies.

Em regiôes costeiras do sudeste do Brasil, Brandini (1986), observou que as concentrações de clorofila $a$ na superficie durante 0 inverno variaram mais intensamente ao longo da costa, enquanto que nas áreas oceânicas as variações foram menos pronunciadas com valores inferiores aos da costa. Costa (1991), comenta que a variação da clorofila $a$ é um reflexo da distribuição quantitativa do fitoplâncton sendo influenciada pelas características nutricionais das diferentes massas d'água.

No estuário do rio Potengi, Oliveira (1985) observou que a clorofila a foi mais elevada na camada de superfície e, quanto à variação sazonal, os picos máximos foram sempre encontrados nos períodos de estiagem, enquanto que Moura (1991) na Baia de Tamandaré, verificou que os valores da biomassa na camada de superficie são sempre inferiores aos encontrados na profundidade do disco de Secchi e que os valores correspondentes a preamar são superiores aos da baixa-mar. Quanto à variação sazonal, os menores índices foram encontrados no período da estação estival.

O estuário do rio Jaguaribe apresentou valores de clorofila a compativeis com os de outros estuários brasileiros e de outras áreas tropicais. $O$ perfil sazonal da concentração de clorofila $a$ total mostra que os valores mais elevados foram registrados nos meses de maior precipitação pluviométrica e os mínimos no período seco. Este 
aspecto foi melhor evidenciado durante a preamar onde observa-se claramente as oscilações entre os dois períodos, embora tenham também ocorrido picos secundários, independente do ciclo de maré. Este padrão foi constatado por Passavante $(1979,1981)$ no Canal de Santa Cruz; Sassi (1987) na Ponta dos Seixas; Brandini, Thamm \& Ventura (1988) na região de Cananéia; Moura (1991) na Baía de Tamandaré; Silva (1992) no estuário do rio Paripe; Koening (1997) no estuário do rio Ipojuca.

Para o estuário do rio Jaguaribe, as concentrações de clorofila $a$ apresentaram uma relação inversa com a maré, em preamar os valores foram sempre inferiores aos obtidos durante a baixa-mar, em reflexo ao grande volume d'água de origem marinha que penetra no estuário que apresentam normalmente uma menor densidade fitoplanctônica, causando assim um efeito de diluição resultando em um padrão no qual a biomassa fitoplanctônica máxima é sempre encontrada em baixa-mar e mínima em preamar. Este padrão também foi verificado por Côté \& Platt (1993), em Bedford Basin (Canadá); e Passavante et al., (1996), em estudos realizados nas Barras de Sapucaí, Sauaçú e Santo Antônio (Paripueira, AL).

O mesmo padrão não foi observado no Estero de Punta Banda, na Baixa Califórnia, pois estudos realizados por Muñoz-Anderson \& Millan-Núñez (1991) mostraram que a concentração de clorofila a apresenta uma sequiencia onde os valores mais elevados são sempre encontrados em regime de preamar e durante as marés de quadratura, tanto a amplitude de variação quanto as concentrações são máximas na época de verão, devido a uma maior temperatura e a um maior tempo de residência do fitoplâncton no corpo d'água.

A biomassa fitoplanctônica quando analisada pelo método de Lorenzen (1967), apresenta vantagens sobre o método de Parsons \& Strickland (1963) pela possibilidade de avaliar os teores de feopigmentos, no entanto, na análise destes pigmentos muitas vezes são obtidos valores negativos, o que seria biologicamente impossivel.

De acordo com Lorenzen (op. cit.), as possibilidades de erro com aplicação deste método, aumenta à medida que as concentrações de clorofila diminuem. Desta forma, quando no ambiente existe uma maior concentração de feopigmentos em relação à clorofila $a$, os dados obtidos com a análise, aplicados na equação resultarão em valores negativos, o que leva a muitos pesquisadores considerá-los nulos.

Em regiōes costeiras e estuarinas, tem sido constatado que a concentração destes pigmentos em muitas ocasiões superam a clorofila $a$, como registrado por Sassi (1987) na região costeira da Ponta do Seixas (PB), Resurreição (1990), na Plataforma continental de Pernambuco em frente ao porto do Recife, Moura (1992) no estuário do rio Paraíba do Norte (PB), Moreira (1994) no estuário do rio Cocó (CE).

No estuário do rio Jaguaribe, as concentrações de feopigmentos foram elevadas e em várias ocasiões foram constatados valores negativos, o que indica que na região estes pigmentos alcançam valores superiores aos da clorofila $a$, sendo provavelmente da degradação da matéria orgânica originada das macroalgas bentônicas que são transportadas para o estuário, da vegetação ciliar, do manguezal e das excreções dos organismos zooplanctônicos, nectônicos e planctônicos.

O fracionamento do fitoplâncton em várias classes de tamanho tem sido freqüentemente estudado em vários ambientes marinhos. Muitos pesquisadores se referem ao fitoplâncton, no que diz respeito às classes de tamanho, como nanoplâncton 
e microplâncton. Geralmente o termo nanoplâncton é designado para os organismos menores que $20 \mu \mathrm{m}$ e microfitoplâncton àqueles maiores que $20 \mu \mathrm{m}$ (Revelante \& Gilmartin, 19\%6; Malone et al., 1980; Malone, 1982).

A fração do nanofitoplâncton é ncrmalmente, responsável por 80 a 100\% da produtividade e biomassa primária em águas temperadas e tropicais, sendo ainda, relativamente mais importantes em águas oceânicas tropicais, onde a produtividade do microfitoplâncton é relativamente mais alta em regiões neríticas (Revelante e Gilmartin, 1976).

O nanofitoplâncton tem sido comumente considerado como a fração predominante em ambientes oligotróficos (Malone, 1971). Tenenbaum et al. (1996) ressaltam estas afirmações, quando verificaram que a comunidade fitoplanctônica na Zona Econômica Exclusiva do Brasil $\left(15^{\circ}\right.$ a $\left.22^{\circ} \mathrm{S}\right)$ apresenta uma predominância do nanofitoplâncton, acima de $90 \%$, comentando que a oligotrofia da região se manifesta através das baixas concentrações celulares, do pequeno porte dos constituintes microfitoplanctônicos e do predomínio do nanoplâncton.

Na Baia de Todos os Santos, Baixa Califörnia (México), Míllan-Núñez \& Loya-Salinas (1993) revelaram que em baixas concentrações de fósforo, foram observadas altas densidades de nanoflagelados, demonstrando a eficiência das células menores na absorção dos nutrientes.

No Mar Adriático, Revelante e Gilmartin (1976) mostraram que o nanoplâncton domina a comunidade fitoplanctônica, representando 80 a $99 \%$ da densidade populacional, todavia, todos os máximos significantes do número de células, biomassa e produção primária, resultaram do aumento dos componentes do micrcfítoplâncton, exceto durante a estratificação do verão quando o nanoplâncton dominou a comunidade.

Em Chesapeake Bay (USA), McCarthy et al. (1974) constataram que a fração $<35$ um foi responsável por $89 \%$ da produção fitoplanctônica. No Gulf of Trieste, Mar Adriático, Malej et al. (1995) observaram que a fração de 2 a $10 \mu \mathrm{m}$ contribuíram significantemente para a produtividade, no entanto, para a média anual, o'mais importante produtor foi a fração $>10 \mu \mathrm{m}$.

No Brasil, estudos do fracionamento do fitoplâncton têm mostrado que, tanto em regiões estuarinas como em outras áreas costeiras, a expressiva contribuição em termos de produção primária é fornecida pelo nanofitoplâncton.

Teixeira et al. (1967), estudando a região de Cananéia (SP), mostraram que a fração entre 5-65 $\mu \mathrm{m}$ foi responsável, em média, por $61,8 \%$ da produção primária.

No nordeste do Brasil, Passavante $(1979,1981)$, estudando o fracionamento da comunidade fitoplanctônica do Canal de Santa Cruz (PE), considerou como nanoplâncton a fração $<45 \mu \mathrm{m}$, a qual representou um percentual entre 31 a 100\% do fitoplâncton total e que os menores valores dessa fração coincidiram, geralmente, com os florescimento das diatomáceas dominantes.

No estuário do rio Ipojuca, Koening (1997) verificou uma sazonalidade em relação as frações, havendo um predomínio da fração do nanofitoplâncton no período chuvoso, compreendendo entre 50 a $80 \%$ da denisidade fitoplanctônica total e da fração do microfitoplâncton no período seco, a qual correspondeu de 30 a $90 \%$ do fitoplâncton total. 
No estuário do nio Paraíba do Norte, Moura (1992) estudando a variação diuma e sazonal, constatou que as constantes substituições das espécies dominantes foram observadas em cada fração analisada (<5; entre 5 e 10; entre 10 e 20 e $>20 \mu \mathrm{m}$ ).

Lara-Lara et al. (1993), comentam que no Golfo da Califórnia (México) o nanoplâncton foi o principal contribuinte das taxas de produtividade primária e de concentração de clorofila $a$, sendo que o domínio do nanoplâncton sobre o microplâncton é devido a estabilidade da coluna d'água, no entanto o máximo de clorofila $a$ e de produção primária ocorreram quando o microplâncton predominou, demostrando que o nível de contribuição do nanoplâncton aumenta quando o total de clorofila decresce.

No estuário do rio Jaguaribe durante o período estudado, a fração dos organismos entre 0,45 a $20 \mu \mathrm{m}$ dominou a comunidade fitoplanctônica representando 64 a $92 \%$ da clorofila total. $O$ aumento da densidade fitoplanctônica $\left(n^{\circ}\right.$ de células $\left.\cdot L^{-1}\right)$ durante os meses de maior incidência pluviométrica não afetou os valores relativos entre as frações do nanoplâncton e do microplâncton, no entanto, a ocorrência de florescimentos esporádicos nos meses de verão ocasionaram um aumento da fração entre 0,45 e $20 \mu \mathrm{m}$ e conseqüentemente um declínio das frações maiores que $20 \mu \mathrm{m}$ em termos relativos. Resultado similar foi obtido por Passavante $(1979 ; 1981)$ no Canal de Santa Cruz (PE), quando revela que na ocorrência de florescimentos esporádicos de alguns organismos diminui a percentagem de uma das frações e aumenta a outra.

Já os valores médios relativos às frações entre 20 e $50 \mu \mathrm{m}$ e maiores que 50 $\mu \mathrm{m}$ sobrepuseram-se àqueles obtidos em baixa-mar, evidenciando que neste ambiente os organismos do pico e nanoplâncton exibiram uma relação inversa com o ciclo da maré

Côté \& Platt (1983) revelaram que os picos da biomassa fitoplanctônica em Bedford Basin, foram sempre durante a baixa-mar, neste sentido, a altura da maré é importante, devido as baixas concentrações fitoplanctônicas presentes na água que entra com o fluxo da maré.

MoCarthy et al. (1974) em Chesapeake Bay, demostraram que a fração menor que $35 \mu \mathrm{m}$ foi responsável por $89,6 \%$ da produtividade do fitoplâncton.

Na Baía de Ubatuba, Teixeira (1973), ressalta a influência dos parâmetros hidrológicos e climatológicos nas variações sazonais da produção biológica da região, registrando uma produção fitoplanctônica alta no verão e baixa no inverno, sendo ainda controlada pela quantidade de sais nutrientes disponíveis.

Millán-Núñez et al. (1993), estudaram a produção primária e clorofila a na parte central do Golfo da Califórnia, observaram uma distribuição variável da concentração de clorofila $a$ devido os processos de mistura que ocorrem nesta zona. Os valores da região sul decrescem da costa para o mar aberto.

Maceno-Silva \& Brandini (1990), objetivando relacionar a biomassa fitoplanctônica às condições hidrograficas na plataforma do Estado de Santa Catarina, encontraram valores máximos nas estações costeiras, diminuindo em direção às áreas oceânicas.

Souza (1996), no sistema estuarino Piaui-Fundo-Real (SE), verificou que a biomassa fitoplanctônica foi maior na porção de maior influência fluvial do estuário e o total de sólido em suspensão foi alto durante todo o ano, sendo os maiores valores 
coincidentes com os da clorofila, contestando a hipótese do incremento da biomassa pela turbidez.

Os resultados obtidos no estuário do rio Jaguaribe mostraram que nos meses de junho e julho, onde ocorreu uma maior precipitação pluviométrica e, consequentemente, maior quantidade de material em suspensão, foram registrados os mais baixos índices de transparência da água. Entretanto, neste período um considerável aumento das concentrações de clorofila a foi verificado principalmente na porção inferior do rio. Este resultado pode ser justificado, pela capacidade que os organismos fitoplanctônicos apresentam, produzindo uma maior quantidade de cloroplastos, em respostas à diferentes intensidade luminosas.

Fato semelhante também foi observado por Koening (1997), no estuário do rio Ipojuca (PE), onde a autora relaciona valores elevados de clorofila $a$ com o aumento de turbidez da água e a baixa intensidade luminosa, e que nestas condições as espécies produziram um maior número de cloroplastos.

\section{REFERÊNCIAS BIBLIOGRÁFICA}

ANDRADE, G. O. de. Itamaracá: Contribuicão para o estudo geomorfológico da costa permambucana. 1955. Imp. Of. Recife, 84p.

BRANDINI, F. P. Hidrografia e Caracteristicas do Fitoplâncton da Região Sueste do Brasil: Producão primária, Biomassa e Composição. São Paulo, 1986. 51 f. Tese (Doutorado em Ciências), Instituto Oceanográfico, Universidade de São Paulo.

BRANDINI, F. P., THAMM, C. A., VENTURA, I. Ecological studies in the Bay of Paranagua. III Seasonal and spatial variations of nutrients and chlorophyll $a$. Pontal do Sul. Nerítica, v.3, n.1, mar, p. 1-30, 1988.

COSTA, K. M. P. da. Hidrologia e biomassa primária da região Nordeste do Brasil entre as latitudes de $8^{\circ} 00^{\prime} 00^{\prime \prime}$ e $2^{\circ} 44^{\prime} 30^{\prime \prime} \mathrm{S}$. e longitudes de $35^{\circ} 56^{\circ} 39^{\prime \prime}$ e $\mathbf{3 1}^{\mathbf{4}} \mathbf{4 8}^{\mathbf{9}} \mathbf{0 0}^{\mathbf{9}} \mathbf{W}$. Recife, 1991, 217 f. Dissertação (Mestrado em Oceanografía Biológica). Departamento de Oceanografia, Universidade Federal de Pernambuco.

CÔTÉ, B., PLATT, T. Day to day variations in the Spring-Summer photosynthetic parameters of coastal marine phytoplankton. Limnology and Oceanography, v. 28 , n. 2, p. 320-344, 1983.

CREITZ, G. I., RICHARDS, F. A. The estimation and caracterization of populations by pigments analysis. III. A note on the of Millipore membrane filter in the estimation of plankton pigments. Journal of Marine Research, New Haven, v. 14, n.3, p. 211-6, 1955.

ESKINAZI-LEÇA, E. Estudos ecológicos do fitoplâncton na plataforma continental de Pernambuco. In: ENCONTRO BRASILEIRO DE PLÂNCTON, 4, 1990. Programa e Resumos .o. Recife: Universidade Federal de Pernambuco, 1990. p.54. ESKINAZI-LEÇA, E., SILVA-CUNHA, M. G. G., KOENING, M. L. Variação espaço-temporal do fitoplâncton na plataforma continental de Pernambuco, in: CONGRESSO LATINO AMERICANO DE FICOLOGIA, 3., REUNIÓN IBEROAMERICANA DE FICOLOGIA, 1., CONGRESSO MEXICANO DE FICOLOGIA, 1., 1993, MEXICO, D.F. Resumenes ... , MEXICO, D.F.: Sociedad Ficologica de America Latina y el Caribe: Sociedad de Mexico: Sociedad Espanola de Ficologia, 1993. p. 121. 
FEITOSA, F. A do N. Produção primária do fitoplâncton correlacionada com parâmetros bióticos e abióticos na Bacia do Pina (Recife-PE). Recife, 1988279 f. Dissertação (Mestrado em Oceanografia Biológica) Departamento de Oceanografia, Universidade Federal de Pernambuco.

FEITOSA, F. A. do N., PASSAVANTE, J. Z. de O. Variação sazonal da biomassa primária do fitoplâncton da Bacia do Pina (Pernambuco - Brasil). Trabalhos Oceanográficos da Universidade Federal de Pernambuco, v. 21, p. 33-46, 1990.

FIDEM - FUNDAÇÃO. DE DESENVOLVIMENTO DA REGIÃOO METROPOLITANA DO RECIFE. Região metropolitana do Recife: Plano de Desenvolvimento Integrado de Itamaracá Recife, 1986.317 p.

FOGG, G. E. Primary Productivity. In: Rilley, J. P., SKIRROW, G. (eds). Chemical Oceanography. London. Academic Press, 1975. p. 386-444.

KOENING, M. L. Ecologia e dinâmica do fitoplâncton no estuário do rio Ipojuca, após a implantação do porto de Suape (PE-Brasili). Recife, 1997. 263 f. Tese (Doutorado), Departamento de Botânica, Universidade Federal Rural de Pernambuco.

LARA-LARA, J.R, MILLÁN-NÚÑEZ, R,LARA-OSORIO, J.L. et al. Productivity y biomass del fitoplancton en la parte central del Golfo de California durante primavera 1985, Ciencias Marinas, Mexico, v. 19, n. 2, p. 137-154, 1993.

LORENZEN, C. J. Determination of chlorophyll and pheopigmentos: spectrofotometric equations. Limnology and Oceanography, Baltimore, v. 12, n. 2, p. 343-6. 1967.

MACENO SILVA, J. R. B., BRANDINI, F. P. Fitoplâncton e características oceanográficas da plataforma de Santa Catarina. In: ENCONTRO BRASILEIRO DE PLÂNCTON, 4, 1990. Programa e Resumos ... Recife: Universidade Federal de Pernambuco, 1990. p.43.

MALEJ, A, MOZETIC, V. TERZIC, S., AHEL, M. Phytoplankton responses to freshwater inputs in a small semi-inclosed (gulf of trieste, Adriatic Sea). Marine Ecology Progress Series, v. 120, p. 111 - 121, 1995.

MALONE, T. C. The relative importance of nannoplankton and net plankton as primary producers in tropical oceanic and neritic phyttoplankton communities. Limnology and Oceanography, Baltimore, v. 16, n. 4, p. 633-639, 1971.

MALONE, T. C. Phytoplankton photosynthesis and carbon specific growth: light saturated rates in a nutrient rich environment. Limnology and Oceanography, Baltimore, v. 17 p. $226-235,1982$.

MALONE, T. C., GARSIDE, C., NEALE, P. J. Efects of silicate depletion on photosynthesis by diatoms in the plume of the Hudson River. Marine Biology, Heidelberg, v. 58, n. 3, p. $197-204,1980$.

MARSHALL, H. G., NESIUS, K. K. Phytoplankton composition in relation to primary production in Chesapeake Bay. Marine Biology, Heidelberg v.125, n. 3, p. 611617, 1996.

MCCARTHY, J. J., TAYLOR, W. R, LOFTUS, W. E. Significance of nanoplankton in the Chesapeake Bay estuary and problems associated with the measurement of nanoplankton productivity. Marine Biology, Heidelberg v.24, n. 1, p. 7-16, 1974. 
MILLÁN-NÚÑEZ, E., LOYA-SALINAS, D. H. Phytoplankton temporal variability in a coastal area of northwestern Baja California. Ciencias Marinas, Mexico, v. 19, $\mathrm{n}$.

1, p. 61-74, 1993.

MOREIRA, M O. P. Produção do fitoplâncton em um ecossistema estuarino tropical (Estuário do Rio Cocó, Fortaleza, Ceará). Recife, 1994. 338 f. Dissertação (Mestrado em Oceanografia Biológica), Departamento de Oceanografia, Universidade Federal de Pernambuco.

MOURA, A do N. Estudo quali-quantitativo da algas perifiticas dos estuários dos rios Paripe e Igarassu - Itamaracá (Pernambuco - Brasil). Recife 1991. 163 f. Dissertação (Mestrado em Botânica) - Universidade Federal Rural de Pernambuco.

MOURA, G. F. de, Comportamento diurno e sazonal de parâmetros fitoplanetônicos e hidrológicos no estuário do rio Paraíba do Norte, Estado da Paraíba, Brasil. Recife, 1992, 206 f. Dissertação (Mestrado em Oceanografia Biológica). Departamento de Oceanografia, Universidade Federal de Pernambuco.

MOURA, R. T. de, Biomassa, produção primária do fitoplâncton e alguns fatores ambientais na Baía de Tamandaré, Rio Formoso, Pernambuco, Brasil. Recife, 1991. 290 f. Dissertação (Mestrado em Oceanografia Biológica). Departamento de Oceanografia, Universidade Federal de Pernambuco.

MUÑOZ-ANDERSON, M. A. MILLÁN-NÚÑEZ, R. Annual variation of phytoplankton productivity in estero de Punta Banda, B. C. México, Ciências Marinas, Mexico, v.17, n. 2, p. 57-70, Jun. 1991.

OLIVEIRA, D. B. F. de, Produção primária do fitoplâncton do estuário do rio Potengi (Natal - RN). Recife, 1985. 168 f. Dissertação (Mestrado em Oceanografia Biológica). Departamento de Oceanografia, Universidade Federal de Pernambuco.

PARSONS, T. R., STRICKLAND, J. D. H. Discussion of spectrophotometric determination of marine plankton pigments, with revised equations of as certanining chlorophyll a and carotenoids. Journal of Marine Research, New Haven, v. 21, 3, p. 155-63. 1963.

PASSAVANTE, J. Z. de O. Produção primária do fitoplâncton do Canal de Santa Cruz (Itamaracá - PE). São Paulo, 1979. 188 f. Tese (Doutorado em Oceanografia). Instituto Oceanográfico da Universidade de São Paulo.

PASSAVANTE, J. Z. de O. Estudo ecológico da região de Itamaracá, PernambucoBrasil. XIX. Biomassa do nano e microfitoplâncton do Canal de Santa Cruz, Trabalhos Oceanográficos da Universidade Federal de Pernambuco, v. 16, p. 105-156, 1981.

PASSAVANTE, J. Z. de O., FERNANDES, M. A A., SANTOS-FERNANDES, T. L. dos. Variação nictemeral da biomassa fitoplanctônica das Barras de Santo Antônio, Sapucaí e Sauaçuí, Paripueira, Alagoas. In: SIMPÓSIO SOBRE OCEANOGRAFIA - IOUSP, 3, 1996. São Paulo. Resumos ... São Paulo. 1996. p. 11.

RESURREIÇÃO. M. G. Variação anual da biomassa fitoplanctônica na plataforma continental de Pernambuco: Perfil em frente ao porto da cidade do

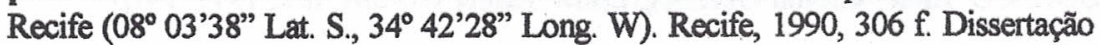
(Mestrado em Oceanografia Biológica). Departamento de Oceanografia, Universidade Federal de Pernambuco. 
REVELANTE, N., GILMARTIN, M. The effect of Po River discharge an phytoplankton dynamics in the northern Adriatic Sea. Marine Biology, Berlim. v. 34, n. 3, p. 259-271, 1976.

SASSI, R. Fitoplâncton da formação recifal da Ponta dos Seixas (Lat. 7009'16'9 Long. 34.47 35\%W) Estado da Paraiba, Brasil: Composição, ciclo anual e alguns aspectos nísico-ccológicos. São Paulo, 1987. 163 f. Tese (Doutorado em Ciências) Instituto Oceanográfico da Universidade de São Paulo.

SILVA, I. G. Variaço sazonal e espacial da produço, biomassa e densidade fitoplanctônica no estuário do rio Paripe (Itamaracá - Pernambuco - Brasil). Recife 1992. 153 f. Dissertação (Mestrado em Botânica) Departamento de Botânica, Universidac'e federal Rural de Pernambuco.

SOUZA, M. F. L. de Variação sazonal da clorofila $a$ e material em suspensão no sistema estuarino Piauí-Fundo-Real, Sergipe. In: SIMPÓSIO SOBRE OCEANOGRAFIA - IOUSP, 1996, São Paulo. Resumos ... São Paulo: 1996. p. 22.

STRICKLAND, J. D. H., PARSONS, T. R. A pratical handbook of seawater analysis. Bulletin Fisheries Research Board of Canada, Ottawa, n. 167, p. 1-311, 1968.

TELXEIRA, C. A. Introdução aos métodos para medir a produção primária do fitoplâncton marinho. Boletim do Imstituto Oceanográlico da Universidade de São Paulo. São Paulo, v. 22, p. 59-92, 1973.

TELXEIRA, C. A., TUNDISI, J. G., SANTORO, J. Plankton studies in a mangrove environment. IV. Size fractionation of the phytoplankton. Boletim do Instituto Oceanográlico, S Paulo, v.16, n. 1, p. $39-42,1967$.

TENENBAUM, D., SAYEG, J., VALETIN, J. L., MAIA, D. B. M., SANTOS, V. S. Aspectos quantitativos do nanoplâncton e microplâncton da zona exclusiva ( $15^{\circ}$ a $22^{\circ} \mathrm{S}$ ) In: SIMPÓSIO SOBRE OCEANOGRAFIA - IOUSP, 1996, São Paulo.Resumos... São Paulo: Instituto Oceanográfico de São Paulo, 1996. p. 3.

TRAVASSOS, P. E. P. F. Hidrologia e biomassa primária do fitoplâncton no estuårio do rio Capibaribe, Recife - Permambuco. Recife, 1991. $287 \mathrm{f}$. Dissertação (Mestrado em Oceanografia Biológica) Universidade Federal de Pernambuco.

TUNDISI, J. G. Produção primária, "standing-stock" e fracionamento do fitoplâncton na região lagunar de Cananéia São Paulo, 1969. 130 f. Tese (Doutorado em Ciências) Faculdade em Filosofia, Ciências e Letras da Universidade de São Paulo.

TUNDISI, J. G. O plâncton estuarino. Contribuições avulsas do Instituto Oceanográfico da Universidade de São Paulo. Série Oceanografia Biológica, São Paulo, n. 19, p. $1-12,1970$.

UNESCO. Determination of photosynthethic pigmens in sea water. Report of SCOR/UNESCO Working group 17 with meat from 4 to 6 june 1964, Paris, 1966. 69p. (Monographys on Oceanology Methodology).

UNESCO. International Oceanographic Table. Wormly, n. 2, 1973. 141p. 